GLORIA M. MORÁN GARCÍA

Universidad de La Coruña, España

\title{
LA CANONÍSTICA MEDIEVAL Y SU CONTRIBUCIÓN AL DESARROLLO DEL PENSAMIENTO CONSTITUCIONAL CONTEMPORÁNEO
}

Sumario: -1 . Consideraciones preliminares. -2 . Orígenes y desarrollo de la noción de soberanía. - 3. La relación entre el poder unipersonal y colegial. - 4. La teoría consensual del poder. - 5. A modo de conclusión.

\section{Consideraciones preliminares}

Decía Bernard Shaw en 1903 con una notable ironía intelectual que el arte de gobernar es la organización de la idolatría. Tal vez en pleno esplendor del hierocratismo -enunciado por Inocencio III, Inocencio IV y Bonifacio VIII- el arte de gobernar la Cristiandad medieval haya facilitado un cierto grado de eclesiolatría y papalatría. Pero sin duda los modelos políticos totalitarios de poder del siglo XX han mostrado con claridad su carácter intrínseco de ídolos falsos a un precio altísimo ${ }^{1}$.

El modelo parlamentario presidencial contemporáneo también parece arrastrar a diversas modalidades ingenuas de idolatría política, desde la democracialatría que nos mostraba el fin de la Historia pronosticado por Francis Fukuyama con el triunfo final de la democracia liberal, a la eurolatría de algunas utópicas doctrinas europeístas, o a la obamalatría de las últimas elecciones presidenciales en Estados

\footnotetext{
${ }^{1}$ Para un análisis detenido vid. G. M. Morán, Comunidad política y religiosa: Claves de la cultura jurídica europea, Netbiblo, La Coruña, p. 66 -92.
} 
Unidos. Ni la democracia puede salvar al mundo de sus males, ni la Unión Europea y el plan de reformas de Obama nos pueden salvar milagrosamente de la grave crisis económica en la que estamos inmersos globalmente. Pero la imperiosa necesidad de la humanidad de construir ídolos, es sólo pareja a su capacidad para destruirlos y sustituirlos por otros nuevos, que crean una vez más falsas esperanzas.

El mundo tiene sus ciclos y en él, el universo de las ideas es un devenir, un proceso sin fin en el que se hibridan circunstancias y reflexiones en la búsqueda del paraíso perdido y la aspiración a un mundo mejor. Un macrocosmos intelectual que requiere no sólo reflexionar hacia adelante, sino también, hacia atrás. Una saludable digestión del pasado desde un horizonte amplio y con la justa dosis de escepticismo que nos libre de idolatrías y autoengaños, resulta necesaria para la legítima esperanza de construir un mundo mejor.

Es por ello por lo que he centrado ésta investigación en la contribución de la canonística medieval ${ }^{2}$ al desarrollo del pensamiento constitucional contemporáneo ${ }^{3}$, pues creo que no ha sido valorada adecuadamente por los teóricos de la ciencia política, que sustancialmente se han desinteresado por ella. A mi juicio las razones de este desinterés son las siguientes:

La aceptación implícita de la división artificial entre Edad Media y Moderna y de sus fronteras ideológicas, en las que la concepción teocéntrica es propia y exclusiva de la Edad Media, y la antropocéntrica lo es de la Edad Moderna. En suma, la aceptación de la división rígida entre la Escolástica y el Racionalismo. El devenir de la historia y del pensamiento político es fruto de un proceso complejo, de una transformación transversal y continua del pensamiento, las circunstancias y su interrelación.

\footnotetext{
${ }^{2}$ Para una visión de conjunto actualizada y con numerosos accesos digitales sobre la transmisión de textos e investigación de las fuentes canónicas, vid. J. SEdANo, Transmisión de los textos e investigación sobre las fuentes históricas del Derecho canónico, Ius Canonicum 50(2010), p. 415-475.

${ }^{3}$ Una contribución sugerente y con una bibliografía completa sobre el pensamiento político medieval es la realizada por B. BAYONA AzNAR, El origen del Estado laico desde la Edad Media, Tecnos, Madrid, 2009, especialmente p. 366-371.
} 
- El mimetismo doctrinal repetitivo de los grandes íconos del desarrollo de las ideas políticas desde el siglo XIV al XVIII: Marsilio, Macchiavello, Bacon, Descartes, Bodin, Grocio, Hobbes, Locke, Montesquieu y Rousseau. Que impiden con frecuencia concebir dicho desarrollo desde postulados que incorporen matices que puedan dar lugar a análisis más creativos y dinámicos y menos dogmáticos y estáticos.

- El profundo desconocimiento de los grandes decretistas y decretalistas, sus reflexiones y su legado en el ámbito público del derecho del siglo XII al siglo XIV.

- La falta de análisis mas completo en el ámbito de la ciencia política de las consecuencias doctrinales del movimiento conciliar del siglo XV, el conciliarismo, y como se introdujeron en la esfera del poder secular ${ }^{4}$.

\footnotetext{
${ }^{4} \mathrm{Si}$ bien existen ya en los años setenta algunos trabajos notables: G. LAGARDE, La naissance de l'esprit laïque au déclin du moyen-âge, vol. 5, 3ed., Louven-Paris 1970; A. Black, Monarchy and Community: Political Ideas in the Later Conciliar Controversy, Cambridge University Press, Cambridge 1971; F. OAKLEY, The 'New Concilliarism' and its Implications: A Problem in History and Hermeneutics, Journal of Ecumenical Studies 8(1971), p. 815-840; H. WALther, Imperiales Königtum, Konziliarismus und Volkssouveranität. Studien zu den Grenzen des mittelalterlichen Souveranitätsgedanken. Wilhelm Fink, München, 1976. También la destacadísima bibliografía de Brian Tierney, citada en estas páginas.

Entre los estudios posteriores con enfoques metodológicos diversos: K. PENNINGTON, Pluralism and the Canonists in the Thirteenth Century, Speculum 51(1976), p. 35 48; Pope and Bishops: The Papal Monarchy in the Twelfth and Thirteenth Centuries (The Middle Ages, University of Pennsylvania Press, Philadelphia, 1984; Law, Legislative Authority, and Theories of Government, 1150-1300, The Cambridge History of Medieval Political Thought c. 350-c. 1450, ed. J.H. Burns, Cambridge University Press, Cambridge 1988, pp. 424-53. (French Translation in: Histoire de la pensée politique médiévale 350-1450, Ed. J.H. Burns; Trans. Jaques Ménard, Presses universitaires de France, Paris 1993, p. 428-49); Popes, Canonists, and Texts 1150-1550 (Collected Studies Series 412), Variorum, Aldershot 1993; The Prince and the Law, 1200-1600: Sovereignty and Rights in the Western Legal Tradition, University of California Press, Berkeley-Los Angeles-London 1993.

Y la obra Conciliarismo y Constitucionalismo. Selección de textos, Colección Politopías. Marcial Pons, Madrid-Barcelona 2005. Introducida por Juan Carlos
} 
- Una escasa valoración comparada de la relación entre las doctrinas absolutistas del poder eclesial y real. Probablemente la doctrina de la ciencia política posterior ha exagerado la incidencia doctrinal hobbesiana del Leviathan en el absolutismo del poder al ignorar o soslayar brillantes formulaciones canonísticas al respecto, que se tuvieron en cuenta para construir la doctrina absolutista del poder al trasladar algunas tesis papalistas al ámbito del poder real.

- Y en fin, una rígida separación ideológica entre el universo doctrinal eclesial o religioso y el secular o laico, que es fruto de las doctrinas de separación Iglesia-Estado y del laicismo ideológico, que puede actuar como filtro interpretativo e introduce una perspectiva metodológica anacrónica al valorar limitadamente:

- Las reformas eclesiales que desde el siglo XII al XVI tuvieron una incidencia directa en el ámbito del poder imperial y real. - Las consecuencias políticas de Reforma protestante y la Contrarreforma tras las paces de Augsburgo y Westfalia, y del desarrollo de la Iglesias nacionales bajo la noción de confesión oficial del Estado.

Por ello estimo necesario un estudio más profundo de las raíces medievales del pensamiento constitucional secular, de la conexión entre la Escolástica y el Racionalismo, y de su transición en el ámbito del derecho político. Es esta pues una invitación a proseguir una línea de investigación iniciada a mediados de la década del siglo pasado sobre todo en el ámbito doctrinal angloamericano, que permita establecer un diálogo doctrinal entre filósofos del derecho, constitucionalistas, politólogos, romanistas y canonistas.

Los presupuestos a tener presentes son a mi juicio los siguientes:

- El desarrollo doctrinal interrelacionado de la eclesiología, el derecho público y la teoría política.

- La importancia del ius commune como derecho común europeo. Un derecho erudito, académico y jurisprudencial enseñado en

Utrera García y con textos de los conciliaristas parisinos: Jean Gerson, John Mair y Jacques Almain. 
las universidades europeas del siglo XII al XVI, que vertebraba el derecho romano-canónico como modelo jurídico de pensamiento en Europa ${ }^{5}$.

- La continuidad del pensamiento jurídico del 1150 al 1650 a través del ius commune y del latín como lingua franca.

- El desarrollo del pensamiento jurídico de los decretistas y decretalistas en el ámbito del derecho público entre los siglos XII y XIV.

- Las consecuencias de las doctrinas conciliaristas sobre todo a partir del siglo XV en el ámbito de la teoría política constitucionalista y su aplicación a modelos representativos seculares.

Dichos presupuestos ponen de relieve que las grandes contribuciones de la canonística medieval al pensamiento constitucional son desde mi punto de vista principalmente tres, y están estrechamente relacionadas entre sí:

a) En el desarrollo de la noción de soberanía.

b) En el desarrollo de la relación entre el poder unipersonal y el colegial.

c) En el desarrollo de la teoría consensual del poder.

\section{Orígenes y desarrollo de la noción de soberanía}

El término soberanía se emplea en el ámbito jurídico público principalmente a partir de la clásica definición de Jean Bodin ${ }^{6}$ del

${ }^{5}$ Como afirma A. Fernández Barreiro, en El humanismo y su influencia en la renovación de la cultura jurídica moderna, Studia et Documenta Historiae et Iuris 69(2003), p.430: "resulta constatable en el siglo XV la presencia de los juristas con formación romano-canónica en todos los ámbitos de la vida social y política relacionados con el derecho, y por tanto en la esfera civil como en la eclesiástica. Controlan el acceso a la profesión jurídica mediante la organización de la enseñanza universitaria del derecho; intervienen en la determinación de los contenidos de la normatividad, y se convierten en los exclusivos operadores jurídicos en la práctica del derecho" (...). "Los juristas se convierten, así, en un grupo profesional de élite, cuyos servicios son solicitados por los particulares y por los poderes públicos, civiles y eclesiásticos".

${ }^{6}$ Conviene recordar que Bodin había sido fraile carmelita y que había recibido una formación escolástica primero y humanista después. Su conocimiento del 
último tercio del siglo XVI, que la definía como: "el poder absoluto y perpetuo de la res publica". Una noción que evoluciona con el desarrollo de la teoría constitucionalista del poder a partir del concepto de soberanía popular de John Locke en el siglo XVII ${ }^{8}$, cuyas raíces arrancan del pensamiento medieval relativo a la potestas, la jurisdictio y el consensus.

Es importante tener en cuenta que el mundo medieval europeo no se regía por un simplista absolutismo teocrático, era un mundo en el que el dualismo del poder a partir de la doctrina gelasiana ${ }^{9}$ se asentaba en dos estructuras de gobierno: el papado y el imperio. Las tensiones generadas por la interacción de ambas estructuras con las emergentes monarquías europeas, y su compleja relación con la jerarquía eclesiástica, la nobleza, y los orígenes del gobierno urbano, facilitarán el desarrollo doctrinal del principio de soberanía, principalmente desde las nociones de jurisdictio y potestas.

En el siglo XII la recepción del derecho romano a partir de la codificación justinianea ofrece a los canonistas la posibilidad de

Derecho canónico era sólido. Había sido liberado de sus votos en 1549 y en 1550 enseñó Derecho romano en la Universidad de Toulouse. Fue especialmente sensible a los efectos de la reforma protestante en Francia y a las luchas entre católicos, calvinistas y hugonotes.

${ }^{7}$ Los Seis Libros de La República, 1576, Libro 1, cap. 8. Su acceso internauta en francés original Les Six Libres de la République en edición digitalizada presentada por G. MAIRET, Le livre de poche, LP17, no 4619, Librairie générale française, Paris 1993

http://classiques.uqac.ca/classiques/bodin_jean/six_livres_republique/six_livres_republique.html

Traducción inglesa Six Books of the Commonwealth en http://www.constitution.org/ bodin/bodin_.htm (Chapter X, p. 40 del texto original en francés).

${ }^{8}$ Two Treatises of Government, 1690. Edición manejada de Thomas Hollis, A. Millar et al., London 1764, disponible digitalmente en http://oll.libertyfund.org/index. php?option=com_staticxt \&staticfile=show.php\%3Ftitle=222\&Itemid=99999999. El segundo tratado se encuentra también disponible en el Proyecto Gutenberg http:// www.gutenberg.org/ebooks/7370

${ }^{9}$ Una interpretación sugerente del dualismo gelasiano desde la sociología puede verse en M. Rhonheimer, Cristianismo y laicidad: Historia y actualidad de una relación compleja, Rialp, Madrid 2009, p. 42-50. 
explorar doctrinalmente el mundo jurídico ${ }^{10}$ más allá de un derecho consuetudinario, incapaz de afrontar los grandes retos de la sociedad medieval que superaba el feudalismo y se adentraba en un modelo social urbano.

Filósofos, teólogos y juristas medievales exploran intelectualmente las nociones de poder, consentimiento y jurisdicción, en el contexto de las circunstancias históricas del momento en que vivían.

Las controversias generadas por la concepción dual del poder, que se agravaron especialmente durante el conflicto de las investiduras del siglo XI, contribuyeron a formular doctrinalmente un primer derecho constitucional canónico desde el legado jurídico romano.

A su vez, de mediados del siglo XII a mediados del siglo XIII, el redescubrimiento de la filosofía política aristotélica a través de comentaristas islámicos, especialmente su obra La Política, facilitó la incursión de los canonistas en la indagación de las teorías políticas del poder y la legitimidad para su ejercicio desde una doble base doctrinal:

- La que aportó la reforma gregoriana, desde el influjo de la reforma cluniacense, sobre la necesidad de la independencia de la Iglesia del poder imperial.

- La construcción del poder jurisdiccional del papado, desde la base ideológica medieval que ofrecía el emergente modelo monárquico de poder a partir de la noción de imperium.

- Así pues los canonistas y civilistas medievales reflexionan, tanto sobre el delicado equilibrio entre el poder pontificio y el imperial, como sobre el poder imperial frente al creciente poder real de los llamados reinos exentos. Este último apoyado doctrinalmente por los canonistas papalistas como estrategia para limitar el poder imperial frente al propio poder pontificio.

La recuperación del legado jurídico romano justinianeo facilitó el empleo de términos como potestas y jurisdictio, que los canonistas

\footnotetext{
${ }^{10}$ Para una excelente y actualizada visión de conjunto de la historia del Derecho Canónico con acceso digital vid. K. Pennington, A Short History of Canon Law from Apostolic Times to 1917, Catholic University of America, Washington DC. En: http://faculty.cua.edu/pennington/Canon\%20Law/ShortHistoryCanonLaw.htm
} 
y civilistas comenzaron a aplicar al ejercicio público del poder, al gobierno de la res publica. Y hacen suyos los términos romanos plena potestas o plena auctoritas, especialmente cuando Papado e Imperio entran en conflicto como consecuencia de la lucha de las investiduras de los siglos XI y XII primero, y el conflicto entre güelfos y gibelinos más tarde.

En los comienzos del siglo XII desde el legado de las escuelas catedralicias y las primeras escuelas jurídicas de derecho vulgar romano-germano, como la Escuela de Pavía, se funda la Escuela de glosadores de Bolonia.

Irnerio (1050-1130) y sus discípulos Bulgaro (1085-1116), Martino Gosia (i-1167) y Hugo di Porta Ravennate (i-1166/70) llegarán a ser consejeros imperiales de Federico I Barbaroja en la dieta de Roncalia (1154-1158) y participan del debate ideológico entre güelfos y gibelinos, que marcará las luchas entre el poder imperial y papal en el contexto de la ciudades-estado italianas del medioevo.

Posteriormente Giovanni Bassiano (i-1117) y Azo (1150-1225) serán algunos de los juristas romanistas más destacados cuyas construcciones doctrinales abren las puertas a la autonomía de la ciencia jurídica. Graciano (1075-1145/47), considerado padre de la ciencia jurídico-canónica, aplica la técnica glosadora al derecho de la Iglesia armonizando los cánones discordantes en su obra magna el Decretum, que en un tiempo muy breve se convirtió en el libro de texto por excelencia de los juristas europeos de los siglos XII y XIII.

Graciano en la Distinctio 20 de su Decretum diferencia el conocimiento (scientia) del poder jurídico (potestas), una noción que la vincula a la autoridad pública y que abre el cauce al desarrollo doctrinal de la potestas a partir de su significado en el derecho romano.

Más tarde $\mathrm{Azo}^{11}$ establece el vínculo conceptual entre jurisdictio e imperium, que identifica como poder o dominio legítimo y que los

\footnotetext{
${ }^{11}$ Profesor de Derecho canónico y jurista en Bolonia a partir de 1259, se ve obligado a abandonar la urbe entre 1274 y 1278 como consecuencia de su vinculación al partido gibelino.
} 
juristas romanos justinianeos no habían llegado a definir. Para Azo cuando es plenissimo implica la capacidad de legislar ${ }^{12}$.

En el siglo XIII el término jurisdictio fue ampliamente usado por Accursio (1184-1263), discípulo de Azo, en su Glosa ordinaria ${ }^{13}$, pues resultaba especialmente idóneo por su valor etimológico que combinaba la idea de lo justo (ius, iustum, iustitia) con la noción de autoridad ligada al término dicere, que en el ámbito del poder del gobernante calificaba como jurisdictio plena, para diferenciarla de la de los jueces y magistrados. Con ello el poder imperial gozaba de la jurisdictio plena, si bien aceptaba que el poder real también disfrutaba de dicha jurisdicción plena, a su juicio derivada del imperium ${ }^{14}$. Para Accursio el gobernante no recibe el imperium ni del poder del papa ni del pueblo. Y sostenía que nadie tenía el control sobre la legitimidad del poder imperial, ni siquiera el poder religioso, e incluso en su opinión, la donación de Constantino, considerada auténtica entonces, carecía de validez jurídica ${ }^{15}$.

Los decretistas, glosadores del Decretum gracianeo, emplearon el término jurisdictio en sus glosas para afrontar cuatro cuestiones prioritarias en el ámbito de la soberanía eclesiástica: su origen, su contenido, sus límites y su cesación.

Desde mediados del siglo XII los canonistas, fascinados por la idea de la soberanía papal y sus posibles límites, plantean la hipótesis de la destitución pontificia en casos de herejía, simonía o depravación

\footnotetext{
${ }^{12}$ H. Bergman, Law and Revolution. The Formation of Western Legal Tradition, Harvard University Press, Cambridge, Massachusetts \& London, England 1983, p. 290-292.

${ }^{13}$ B. Tierney, Religion, Law and the Growth of Constitutional Thought 1150-1650, Cambridge University Press, Cambridge \& New York 1982, p. 31. Y analizado con más detalle en Church Law and Constitutional Thought in Middle Ages, Variorum Reprints, London 1979, p. 238-256.

${ }^{14}$ B. Bayona Aznar, cit., p. 363.

${ }^{15}$ K. Pennington, Law, Legislative Authority, and Theories of Government, 1150 1300, The Cambridge History of Medieval Political Thought c. 350-c. 1450", cit., p. 432. También recogido por B. BAyona Aznar, p. 363-364.
} 
moral ${ }^{16}$. A partir de entonces dos serán las tesis relativas a la inmunidad papal, una sostiene la imposibilidad de que el papa sea juzgado por una autoridad humana y la otra, en cambio, se afirma que el texto del Decretum de Graciano (D. XL, d. 6) acepta que tal inmunidad quiebra ante supuestos de herejía ${ }^{17}$.

Efectivamente, Graciano recoge en su Decreto algunas cuestiones relativas a papas corruptos que son glosadas por los decretistas y distingue entre herejía y cisma, pues la primera se refiere a dogmas erróneos, y el segundo a separación de un obispo y su diócesis de la comunidad eclesial ${ }^{18}$. Paucapalea ${ }^{19}$ será el primer decretista que afronte la cuestión en el ámbito episcopal pero no en el papal, sobre el que guarda silencio. En cambio el maestro Rufino $(1150-1191)^{20}$ será el primero, a su vez, que traslade la cuestión de la herejía al ámbito papal, si bien no afronta los supuestos de simonía ${ }^{21}$. La Summa Parisiensis elaborada hacia el 1160 considera que es la Iglesia (Ecclesia tota) quien tiene potestad para juzgar a un papa por herejía, y aunque se refiere a la simonía en su obra, no afirma con claridad que ésta quiebre la inmunidad pontificia ${ }^{22}$.

Johannes Teutonicus (1170-1245) ${ }^{23}$ aclara en su Glosa ordinaria fechada hacia el año 1216, que: "El Papa goza de la presunción de santidad, una presunción que acepta prueba en contrario"24. Y para

\footnotetext{
${ }^{16}$ Un sugerente estudio al respecto de J. Moyninan, Papal Immunity and Liability in the Writings of the Medieval Canonists, Gregorian University Press, Roma 1961, en la que el autor explora la cuestión de la inmunidad papal con detenimiento desde el siglo V hasta 1417. Vid. Especialmente p. 42 a 122.

${ }^{17}$ Ibid., p. 42.

${ }^{18}$ Ibid., p. 49.

${ }^{19}$ Considerado el primer discípulo de Graciano y autor de su Summa elaborada entre 1144 y 1150 .

${ }^{20}$ Tal vez discípulo de Graciano, y profesor en Bolonia, en fecha no identificada, y posteriormente obispo de Asís. Elaboró su Summa hacia el 1164.

${ }^{21}$ Ibid., p. 50.

${ }^{22}$ Ibid., p. 52.

${ }^{23}$ Que enseñó Derecho canónico en Bolonia entre 1210-1112 y 1213-18.

${ }^{24}$ Decretum Gratiani...una cum glossis, Venice 1600, Gloss and Dist. 40 c. I, cfr. B. Tierney, Religion Law, cit., p. 16, n. 8. Para su acceso digital completo en
} 
Alanus Anglicus (1190-1215)25: "El Papa sólo puede ser juzgado por herejía, pues en asuntos de fe están por encima el colegio cardenalicio y el concilio episcopal" 26 .

Sobre la cuestión de la potestad papal y su formulación jurídica Huguccio $(i-1210)^{27}$, probablemente el mejor y mayor decretalista de finales del siglo XII, parte de la concepción del origen divino del poder para poder formular con nitidez la distinción entre la autoridad espiritual y temporal, y atribuye al papa la jurisdicción universal exclusivamente en el ámbito eclesiástico. Si bien claramente mantiene una cierta subordinación del poder temporal al espiritual ${ }^{28}$. Alanus Anglicus, en cambio, aunque emplea el término plenitudo potestatis, incluye en él no sólo el poder espiritual sino también el poder temporal del papa ${ }^{29}$.

Estas reflexiones de los decretistas van a facilitar que la potestad temporal del papa se asimile a la potestad de los monarcas, y la canonística medieval se divida doctrinalmente entre los partidarios de una monarquía papal limitada, y los que reafirman las bases de la supremacía papal, formulada jurídicamente en el siglo XIII por los papas canonistas Inocencio III (1198-1216) e Inocencio IV (1243-1254) ${ }^{30}$, cuando las tensiones con el emperador Federico II Hohenstaufen se recrudezcan. Para Inocencio III la plenitudo potestatis papal es incluso supra ius $^{31}$, e Inocencio IV afirma que la potestad plena le permite

latín en la Bayerische Staatsbibliothek http://geschichte.digitale-sammlungen.de/ decretum-gratiani/online/angebot

${ }^{25}$ Canonista de origen anglonormando que enseñó Derecho canónico en Bolonia hacia 1190-1215, y autor de Ius Naturale.

${ }^{26}$ Gloss and Dist. 40, c. 6.

${ }^{27}$ También vinculado a la Escuela de Decretistas de Bolonia, y profesor de Derecho canónico en la misma ciudad, tendrá una influencia sustancial con su obra Summa Decretorum compuesta hacia el año 1187.

${ }^{28}$ B. Tierney, Church Law and Constitutional Thought in Middle Ages, cit., p. 603.

${ }^{29}$ Ibid., p. 603-605.

${ }^{30}$ Ibid., Part 2, Ch. 1, p. 81 y ss.

${ }^{31} \mathrm{X}$, III, viii, 4: Secundum plenitudem potestatis de iure possumus supra ius dispensare. 
ejercer el poder temporal y espiritual no sólo sobre los cristianos sino también sobre los infieles ${ }^{32}$.

La doctrina de la monarquía papal ilimitada va a ser favorecida por la promulgación de las decretales pontificias que refuerzan el poder legislativo papal, a partir de las Decretales de Gregorio IX elaboradas por Raimundo de Peñafort y promulgadas en 1234.

La llamada era de las Decretales papales, que concluye en 1317, orienta el trabajo de los canonistas medievales a partir de entonces a glosar las decretales pontificias, por lo que serán llamados decretalistas para distinguirlos de los decretistas gracianeos, cuya labor declina.

Coincido con la afirmación de Bayona Aznar ${ }^{33}$ respecto a que la primera generación de canonistas del siglo XII mantuvo la distinción ontológica entre el poder temporal y el espiritual desde la influencia de la doctrina del dualismo gelasiano, sin embargo el centralismo pontificio y la doctrina de la plenitudo potestatis formulada por Inocencio III orientarán a buena parte de los canonistas del siglo XIII hacia la defensa de la supremacía pontificia ilimitada, reforzada por la doctrina en la que la intervención pontificia en asuntos temporales se justificaba sobre la base de su jurisdicción universal en asuntos espirituales. Una doctrina que se apoyaba jurídicamente en el activo papel de los pontífices como legisladores y en su actividad conciliar en la etapa posterior a la de los concilios ecuménicos imperiales del primer milenio, que se inicia en el siglo XII con los concilios lateranenses (de 1123, 1139, 1179 y 1215) y prosigue con los dos concilios de Lyon (1245 y 1274) y el concilio de Vienne de 1311-12.

Efectivamente, a lo largo del siglo XIII se consolida progresivamente la doctrina de la monarquía papal ilimitada cuya expresión teórica la formula otro papa canonista, Bonifacio VIII, en la Bula

\footnotetext{
${ }^{32}$ Commentaria ad X, II, ii, 10; III, xxxiv, 8. Analizada por B. Tierney, Foundations of the Conciliar Theory. The Contribution of the Medieval Canonists from Gratian to the Great Schism. (Primera edición Cambridge University Press, Cambridge 1955) edición manejada, Brill, Leiden, N. York, Köln 1998, p. 134-135.

${ }^{33}$ B. Bayona Aznar, cit., p. 367.
} 
Unam Sanctam en 1302, en plena confrontación con Felipe IV de Francia. Una situación que facilita desde comienzos del siglo XIV la emergencia de las doctrinas de la secularización del poder enunciadas por los regalistas de la Escuela de París. Testigos de excepción de esta confrontación fueron Juan de París (1255-1306) ${ }^{34}$ con su obra De potestate regia et papali de 1302, y posteriormente Marsilio de Padua (1275-1342) $)^{35}$ con su obra Defensor Pacis escrita en 1324 y su coetáneo Guillermo de Ockham (1288-1349) ${ }^{36}$ con sus obras Dialogus, Octo questionis y De imperatorum et pontificum potestate ${ }^{37}$. Ambos refugiados en la corte de Luis de Baviera en Munich y en abierto conflicto con el Papado. Dichas obras tendrán una influencia sustancial entre los canonistas, legistas y teólogos de los siglos XIV-XV y en buena parte sientan las bases del pensamiento político laico posterior.

Pocos años antes del traslado de la corte papal a Aviñón en 1294 se produjo la abdicación del papa Celestino $\mathrm{V}^{38}$, el monje benedictino y eremita de los Abruzzo ajeno al mundo burocrático y curial de Roma, que renuncia al papado a los cuatro meses de su elección ${ }^{39}$,

\footnotetext{
${ }^{34}$ Franciscano con formación canonista que enseñó Teología y Filosofía en la Universidad de París, fue apartado de la docencia por el obispo de París y muere en Burdeos poco después de iniciar su proceso de apelación a la Santa Sede.

${ }^{35}$ Dominico, heredero de una tradición familiar de juristas de la ciudad de Padua, es nombrado Rector de la Universidad de París en 1313, cargo que debe abandonar tras la crítica abierta al Papado que le obliga a refugiarse en la corte de Luis de Baviera en 1327, quien lo nombra posteriormente vicario espiritual de la ciudad de Munich, en la que reside hasta su muerte.

${ }^{36}$ Teólogo franciscano educado en Oxford, y defensor de la pobreza, una cuestión que enfrentaba a la orden franciscana con la corte papal aviñonense. Acusado de herejía, acude a la corte papal de Aviñón para su proceso inquisitorial que se inicia en 1324 . Huye en 1328 junto al general de la orden franciscana a la corte de Luis de Baviera, al igual que Marsilio reside también en Munich hasta su muerte.

${ }^{37}$ Para un sugerente trabajo preliminar y el texto completo en castellano vid. G. DE Oскнам, Sobre el poder de los emperadores y los papas. (Trabajo preliminar y traducción J. C. Utrera Garcia) Pons, Madrid-Barcelona 2007, p.11-46, con una selección bibliográfica y de fuentes actualizada y rigurosa).

${ }^{38}$ B. Tierney, Religion, cit., p. 33.

${ }^{39}$ Ego Caelestinus Papa Quintus motus ex legittimis causis, idest causa humilitatis, et melioris vitae, et coscientiae illesae, debilitate corporis, defectu scientiae, et
} 
tras el acceso al papado de su sucesor, Bonifacio VIII, éste da orden de su captura. Celestino V es hecho prisionero y muere casi dos años después.

Una situación que provoca numerosas cuestiones jurídicas en torno no sólo a la abdicación papal, sino también sobre su posible destitución, que se afrontarán de nuevo en 1415 en un contexto diverso, cuando Gregorio XII abdica como consecuencia de la crisis tricefalia pontificia (Gregorio XII, Benedicto XIII y Alejandro V) producida de 1378 a 1417 tras el periodo pontificio Aviñonense.

Una crisis de autoridad que se había iniciado con la bicefalia papal debida a la simultaneidad de dos líneas sucesorias: la de Urbano VI (1378-1389), sucedido por Bonifacio IX (1389-1404) y éste a su vez por Gregorio XII (1406-1415); y la de Clemente VII (1378-1394), sucedido por Benedicto XIII (1394-1423) y a su vez éste por Benedicto XIV elegido en un conclave del todo irregular e ilegítimo.

La bicefalia papal se agravó tras el concilio de Pisa de 1409 con la elección en el mismo de Alejandro V (1386-1410) sucedido por Juan XXIII (1410-1415), pues se transformó en una tricefalia al no renunciar al papado ni Gregorio XII ni Benedicto XIII ${ }^{40}$. Esta crisis de la autoridad pontificia se resuelve en el Concilio de Constanza, convocado por el emperador Segismundo de Luxemburgo en 1413,

malignitate Plebis, infirmitate personae, et ut praeteritae consolationis possim reparare quietem; sponte, ac libere cedo Papatui, et expresse renuncio loco, et Dignitati, oneri, et honori, et do plenam, et liberam ex nunc sacro caetui Cardinalium facultatem eligendi, et providendi duntaxat Canonice universali Ecclesiae de Pastore Celestino V - Bolla pontificale, Napoli, 13 dicembre 1294. Acceso digital en http://www.ghirardacci.it/torelli/1294.htm

Para el bulario de Celestino V http://www.documentacatholicaomnia. eu/01p/1294-1294,_SS_Celestinus_V,_Bullarium_(Cherubini_vol_1_ff_194-198),_ LT.pdf

${ }^{40}$ Por lo que en este periodo de la historia del papado se consideran antipapas: Benedicto XIII de Aviñón (el papa Luna), su sucesor Clemente VIII (arcipreste de Teruel y canónigo de Barcelona), el franciscano Alejandro V de Pisa, cuya legitimidad fue mantenida durante un tiempo de ahí que Alejandro VI, el Papa Borgia, adoptase la numeración de su nombre como papa continuadora del anterior, y Juan XXIII, que había participado como cardenal en el Concilio de Pisa. 
con la mencionada renuncia de Gregorio XII, las destituciones de Juan XXIII y Benedicto XIII y la elección de Martín V en 1417, y con ello se refuerza doctrinalmente la supremacía conciliar.

En el último tercio del siglo XIV durante el Cisma de Occidente, la tesis de la plenitudo potestatis ilimitada entra en crisis en el seno mismo de la Iglesia y los canonistas conciliaristas la rebaten con su interpretación de la potestad plena del concilio ${ }^{41}$. Así las nociones de potestas e universitas adquieren un nuevo sesgo doctrinal, cuando las circunstancias y el desarrollo de la era de los consilia y de los tratadistas facilitan el debate sobre una soberanía dividida. Un debate que se intensifica en los concilios de Pisa (1409) Constanza (1414-1417), Basilea (1431), Ferrara (1438) y Florencia (1445).

Conviene tener presente para no simplificar anacrónicamente las peculiaridades del movimiento conciliar, que ciertamente no fue un movimiento antipapista, sino que cuajará doctrinalmente durante varios siglos a partir de la construcción doctrinal de los límites jurídicos a la formulación del absolutismo pontificio de los siglos XIII-XIV. El conciliarismo provoca una corriente doctrinal que se proyecta y se recibe en la Filosofía política de los siglos inmediatos ${ }^{42}$ cuya influencia en el desarrollo del parlamentarismo europeo será notable, sobre todo a partir del siglo XVII cuando emergen las doctrinas contrarias al absolutismo real que se ponen de manifiesto en las tensiones entre el Parlamento y la corona inglesa que provocan la guerra civil inglesa de 1642-51.

\section{La relación entre el poder unipersonal y colegial}

Los canonistas medievales se mostraron también interesados en formular jurídicamente la relación entre el gobernante y la comunidad. Por ello los decretistas y decretalistas analizaron el contenido de la

\footnotetext{
${ }^{41}$ B. Tierney, Foundations of The Conciliar Theory, cit., p.162-179.

${ }^{42}$ En este sentido J. C. Utrera García, Introducción en Conciliarismo y constitucionalismo, cit. p. 10.
} 
soberanía papal contrastándola con la soberanía imperial, y ambas en relación con las comunidades eclesial y cívica ${ }^{43}$.

Desde los imprescindibles referentes teológicos, el lenguaje jurídico de los canonistas se torna progresivamente menos ambiguo a medida que exploran la relación entre el papa y la comunidad eclesial, desde la noción de la representación jurídica ${ }^{44}$, y especialmente entre la autoridad pontificia y la conciliar.

Para los decretistas de comienzos del siglo XIII aunque el papa es la suprema autoridad de la Iglesia, su poder no era absoluto y se mostraban favorables a la que posteriormente se denominó "soberanía dividida" ${ }^{45}$ entre la unipersonalidad papal y la colegialidad conciliar.

Desde entonces se reconoce la doble distinción jurídica entre: potestate ordininis y potestate jurisdictionis, y entre potestad unipersonal y colegiada.

Así los decretistas entienden que la potestad de jurisdicción aunque ejercida unipersonalmente, la recibe de la Iglesia como entidad corporativa, como universitas ${ }^{46}$.

La universitas es una abstracción jurídica que no es equivalente a la suma de miembros de una entidad, de una comunidad, sino que constituye una res incorporalis, un sujeto no físico de derechos y deberes, capaz de integrar la jerarquía y la colegialidad ${ }^{47}$.

Rufinus, a finales del siglo XII, afirma que el poder pontificio está vinculado a las normas de los Padres de la Iglesia promulgadas para

\footnotetext{
${ }^{43}$ B. Tierney, Religion, cit. p. 13.

${ }^{44}$ Para una rigurosa visión de conjunto K. Pennington, Representation in Medieval Canon Law, The Jurist 64(2004), p. 361-383 y en Reprosentatio: Mapping a Key Word for Churches and Governance: Proceedings of the Sam Miniato International Workshop, October 13-16, 2004, ed. Alberto Melloni and Massimo Faggioli MünsterHamberg-Berlin-Wien-London 2006, p. 21-40. Y el acceso digital en http://faculty. cua.edu/pennington/PenningtonRepraesentationRevised.htm

${ }^{45}$ B. Tierney, Ibid., p. 18.

${ }^{46}$ H. Bergman, Law and Revolution, cit., p. 207.

${ }^{47}$ J. A. Souto Paz, La idea medieval de nación, Cuadernos del Derecho Público 2(1997), p. 124.
} 
preservar la autoridad de la propia Iglesia ${ }^{48}$.Y Huguccio explica que: "Aunque el Papa romano pueda en alguna ocasión errar, ello no significa que la Iglesia romana yerre" ${ }^{49}$. Y aún con total claridad declara que "En asuntos de fe el concilio está por encima de Papa"50. Afirmación que probablemente tenía en cuenta que el papa era parte intrínseca del propio concilio, pues sus afirmaciones tienen lugar dos siglos antes del cisma de Occidente y la tricefalia pontificia del siglo XV.

En todo caso los canonistas abrían la via concilii como solución jurídica a la hipótesis de un papa hereje y otorgaban al concilio la potestad decisoria. A su vez al aplicar la teoría de la representación a la Iglesia se abría, a su vez, el cauce para el desarrollo del concepto congregatio fidelium, que posteriormente permite construir la teoría del oficio eclesiástico y su titularidad vinculada a la Iglesia como congregación de fieles.

Las relaciones entre el papa y los cardenales son objeto de interés para los decretistas ya que el propio Decreto de Graciano recoge su papel en las elecciones pontificias ${ }^{51}$ tras la reforma de Nicolás II en 1059. Los cardenales desde el siglo XI adquieren un papel más destacado como consejeros pontificios y por ello los decretistas incluyen jurídicamente su posición en la Iglesia y se refieren a la Romana ecclesia como al papa et cardinales, si bien éstos se ocupan sobre todo de su papel electoral en sede vacante.

A su vez las relaciones entre el obispo, el cabildo y la diócesis serán también estructuradas jurídicamente a partir de la universitas y de la teoría de la representación, o personificación. Conviene recordar el papel destacadísimo de las órdenes religiosas en estos siglos a partir del modelo benedictino y su regla, y de las subsiguientes reformas de las órdenes monacales así como de la fundación de otras nuevas

${ }^{48}$ B. Tierney, Religion, cit. p. 17, n. 12 citando a su vez la Summa Decretorum des Magister Rufinus. Ed. H. Singer, Padernborn 1902. Disponible digitalmente en http:// www.archive.org/details/diesummadecretor00rufi

${ }^{49}$ Summa ad C.24 q.1 c.9

${ }^{50}$ Gloss and Dist. 40, c.6

${ }^{51}$ Disct.23, c.1 
que dejan de ser estrictamente monacales, especialmente dominicos y franciscanos en el siglo XIII, si bien la estructura jurídica de todas ellas se asienta en la noción jurídica de comunidad religiosa y se reproduce en parte el modelo jurídico eclesial.

En el ámbito de la Iglesia el desarrollo de la noción de universitas propicia los primeros debates entre canonistas papalistas y conciliaristas que ya surgen en el siglo XIII. Mientras los papalistas reclaman la superioridad absoluta del poder pontificio, las primeras corrientes conciliaristas sostienen la superioridad del poder colegiado conciliar.

La noción de universitas, que sirve a los decretistas para construir la estructura colegiada de la Iglesia, procurará el apoyo necesario para el desarrollo posterior de la noción de soberanía real y estatal, desde la noción de reinos exentos del imperio y la máxima: rex, imperator in regno suo ${ }^{52}$.

Acurssio, que como ya indiqué era partidario de que el imperium no lo recibía el emperador de ninguna autoridad humana, afirmaba además la superioridad e independencia del poder real rex superiorem non recognoscens ${ }^{53}$. Así Ricardus Anglicus (1161-1242) ${ }^{54}$ y Laurentinus Hispanus (1200-1248) $)^{55}$, entre otros, atribuyen al monarca un poder autónomo que no deriva ni del papa ni del emperador, sino de la universitas, y atribuyen al monarca jurisdictio e imperium ${ }^{56}$.

Una construcción del poder real que será defendida primero por los legistas castellanos de Alfonso X (1252-1284), que empleaba para

${ }^{52}$ Sobre la ecuación REX=IMPERATOR vid. J. A. Souto PAz, cit., p. 128-132. Sobre su penetración en Francia vid. A. Fernández Barreiro, El humanismo y su influencia en la renovación de la cultura jurídica moderna, cit., p. 446-449.

${ }^{53}$ Recogido por B. BAyonA AzNAR, cit., p. 364.

${ }^{54}$ Canonista anglonormando, probablemente educado en Lincoln y la Sorbona, profesor en Bolonia entre 1191 y 1202, y decano de la Facultad de Derecho en 1226.

${ }^{55}$ Profesor de Derecho canónico en Bolonia entre 1200 y 1214, nombrado obispo de Orense en 1218, ciudad en la que reside hasta su muerte en 1248. Canonista enormemente creativo cuyas obras más influyentes son la Glossa Palatina sobre el Decreto de Graciano y sus glosas a la Compilatio tertia, que a su vez serán citadas en las glosas de los decretalistas a las Decretales de Gregorio IX, así como su trabajo será recibido por G. de Baysio.

${ }^{56}$ B. Tierney, Religion, cit., p. 22. También en J. A. Souto Paz, cit., p. 130-132. 
sí el título de emperador y equiparaba al de $\mathrm{rey}^{57}$, y después por los legistas franceses de Felipe IV (1285-1314) quien -tras las tensiones con Bonifacio VIII que sientan las bases del galicanismo en su formulación más temprana- contará con el apoyo de los papas franceses, especialmente Clemente V y Juan XXII, y los canonistas de la corte papal de Aviñón, quienes favorecen dicha construcción doctrinal como estrategia jurídica para limitar en poder imperial. Recordemos en este punto el abierto conflicto entre Juan XXII y el emperador Luis IV de Baviera (1328-1347) a quien excomulga en 1324 por dar amparo en su corte a Marsilio de Padua, y los franciscanos Guillermo de Ockham y Miguel de Cesena, todos ellos muy críticos con el poder pontificio de la etapa aviñonense.

Posteriormente, a comienzos del siglo XIV, los juristas napolitanos trasladaron la estructura del derecho imperial al derecho real de los monarcas en la confrontación entre los emperadores germanos y Roberto I de Anjou, rey de Nápoles (1309-1343) y líder güelfo que contaba con el apoyo papal. Primero se enfrentó al emperador Enrique VII entre 1311 y 1313, que ocupó Roma con sus tropas en 1312, y después a Luis IV de Baviera en 1318. En las tensiones entre poder papal, imperial y real y sus formulaciones jurídicas encontramos las raíces de la teoría del Estado nacional.

A partir del concepto de universitas se construye la teoría de la persona jurídica que será sintetizada con brillantez por Giovanni Andrea $(1270-1348)^{58}$, el canonista más prestigioso de la primera mitad del siglo XIV y uno de los últimos representantes de la escuela de los glosadores decretalistas. Y la teoría de la persona representata será

\footnotetext{
${ }^{57}$ Siete Partidas (Prólogo) y Partida 1a, título 1, ley 12. Vid. Edición digital (texto escaneado del original de 1807) http://fama2.us.es/fde/lasSietePartidasEd1807T1. pdf

Sobre el poder, su origen y finalidad Partida 2a títulos 2 a 14 http://fama2.us.es/fde/ lasSietePartidasEd1807T2.pdf

${ }^{58}$ Alumno en Bolonia de los mejores romanistas y canonistas del momento, enseñó Derecho canónico en Padua y en Bolonia desde 1301 hasta 1348, donde muere a causa de la gran plaga. Amigo de Petrarca y Cino di Pistoia, nunca fue clérigo, sino un laico casado y padre de familia.
} 
retomada por los comentaristas, cuyo método cobra fuerza a mediados del siglo XIV.

Por otra parte conviene tener presente que esta etapa de la historia se verá permeada por los postulados aristotélicos de los que la teología y la filosofía se hacían eco -desde el ejemplo de Tomás de Aquino (1225-1274) y su ingente obra doctrinal- lo que permitió que la teología cristiana cobrase un notable desarrollo doctrinal, especialmente después de 1325, cuando se levanta la condena impuesta por el obispo de París sobre numerosas de las tesis del aquinate.

El impulso de la filosofía aristotélica desde la teología coincide con el declive de la canonística, aún aferrada al método de la glosa, creándose numerosas tensiones entre ambos saberes en el ámbito académico ${ }^{59}$, lo que en parte propicia el declinar de la canonística boloñesa.

Con la decadencia de la glosa y de la Escuela boloñesa en el siglo XIV, emerge el método jurídico del comentario en el entorno académico de la Escuela de Orleans $s^{60}$. Que ya a mediados del siglo XIII desarrolla una orientación doctrinal propia a partir de la formación jurídica romano-canónica. Una orientación que contribuye a la educación de los consejeros legistas de la monarquía franca, y de la que parte el desarrollo de las doctrinas galicanas, así como se sientan las bases del derecho nacional francés.

La inicial figura de la Escuela de Orleans es Jacques de Révigny. Su aportación más destacada en el ámbito del derecho público fue la de construir doctrinalmente el poder real del monarca francés a partir del derecho público romano. Para ello Révigny emplea la noción de persona jurídica, persona representata, y la vincula a la titularidad

\footnotetext{
${ }^{59} \mathrm{Al}$ respecto vid. H. WALther, Una relación complicada. Los juristas y Aristóteles, Patristica et Mediaevalia 22 (2001), p. 3-16 (referido por B. Aznar, p. 415).

${ }^{60}$ Sobre la Universidad de Orleans a partir del siglo XIII vid. A. FernándeZ BARREIRO, cit., p. 446 y las referencias bibliográficas en su nota 72. En especial E. M. Meijers, L'Université d'Orleans au XIII siècle”. Études d'Histoire du droit, publicado por Feenstra y Fisher, Universitaire Pers Leiden, Leiden 1959; y B. PARADISI, La scuola di Orleans. Un'epoca nuova nel pensiero giuridico, Studia et Documenta Historiae et Iuris 26(1960), p. 347 y ss.
} 
del imperium y de la iurisdictio, por lo que se elabora un concepto abstracto de soberanía, que permite el desarrollo de la noción jurídica de Estado ${ }^{61}$. Una construcción doctrinal que completa Pierre de la Belleperche al admitir la pluralidad de titulares del poder ${ }^{62}$. Cino di Pistoia (1270-1336), amigo de éste último, introdujo y perfeccionó el método del comentario en Italia que pronto será utilizado en las nuevas universidades fundadas por emperadores y monarcas, lo que facilita un importante desarrollo del derecho público imperial y real en torno a la noción de la res publica christiana.

Bartolo di Sassosferrato (1314-1357) ${ }^{63}$ contribuirá sustancialmente a desarrollar el origen de la soberanía en el ámbito urbano de las ciudades italianas a partir de la noción de jurisdictio desarrollada por Accursio, que le permite elaborar el concepto de status civitatis, por el que el ciudadano se sometía a la jurisdicción urbana ${ }^{64}$, puesto que tenía plenam potestatem. Su discípulo Baldo de Ubaldis (13271400), que a su vez fue maestro de Francisco Zabarella y del futuro papa Gregorio XI (último del periodo Aviñonense) y consejero del papa Urbano VI durante el cisma de Occidente, identifica el poder político con la potestad plena, por lo que supera su equiparación con la potestad universal y suprema. Una expresión que ya venía siendo ampliamente utilizada en el ámbito urbano de este periodo.

Efectivamente, la plenam potestatem era la expresión empleada por los canonistas en la doctrina de la representación corporativa, tomada del derecho romano, que cobra un nuevo significado en el contexto de la universitas urbana. Un término usado ya por el papa Inocencio III en el 1200 cuando convoca a los representantes cum plena potestate de las ciudades de los Estados Pontificios. Y un término que posteriormente empleará el parlamento inglés a partir de $1268^{65}$.

\footnotetext{
${ }^{61}$ En este sentido B. Bayona Aznar, cit., p. 372.

${ }^{62}$ Ibid.

${ }^{63}$ Alumno de Cino de Pistoia, maestro de Baldo de Ubaldis, profesor de Derecho civil en Perugia y Bolonia, y un jurista clave en la construcción del utrumque ius, fue consejero del emperador Carlos IV de Luxemburgo.

${ }^{64}$ B. Bayona Aznar, ibid., p. 375.

${ }^{65}$ B. Tierney, Religion, cit., p. 24.
} 
La noción de corporación pública en Derecho canónico medieval, tanto en la Iglesia universal como en la diocesana, facilitarán en el ámbito secular dos modelos de representación jurídica sustanciales en el constitucionalismo contemporáneo ${ }^{66}$ :

- La representación como la personificación de la comunidad a través su máxima autoridad unipersonal.

- La representación como la delegación de autoridad de la comunidad a un sujeto.

Al aplicar la teoría del derecho corporativo a la Iglesia los canonistas elaboran la estructura de la delegación de los oficios eclesiásticos ${ }^{67}$.

Una construcción jurídica que nos lleva directamente a la teoría del consentimiento en el ámbito público.

\section{La teoría consensual del poder}

Sin duda una de las contribuciones más notables de los canonistas medievales al pensamiento constitucional contemporáneo ha sido la doctrina del consentimiento consagrada en la máxima legal romana: quod omnes tangit ab omnibus approbetur (lo que concierne a todos debe de ser aprobado por todos), que en el código justinianeo se aplicaba en el ámbito del derecho privado ${ }^{68}$. Los canonistas medievales la expandirán al ámbito público de la Iglesia y de los reinos. Y posteriormente será asimilada progresivamente por el pensamiento político secular.

${ }^{66}$ Ibid., p. 27.

${ }^{67}$ En este sentido J. C. Utrera García, Conciliarismo y constitucionalismo. Introducción, cit., p. 14. Sobre esta cuestión W. MAGER, Res publica chez les juristes, théologiens et philosophes à fin du Moyen Âge: sur l'elaboration d'une notion-clé de la théorie politique moderne. Théologie et droit dans la science politique de l'État moderne. Rome 1991.

${ }^{68}$ Codex Justinianus 5, 59, 5. Para el acceso digitalizado al texto fotográficamente reproducido del vol. 2 de la edición de Mommsen y Krueger de 1888 http://www.archive.org/details/corpusjuriscivil00krueuoft

Para una reciente visión de conjunto desde la perspectiva libertaria vid. C. WATnER, Quod omnes tangit: Consent Theory in the Radical Libertarian Tradition in the Middle Ages, Journal of Libertarian Studies 19(2005)2, p. 67-85. Acceso digital en: http://mises.org/journals/jls/19_2/19_2_4.pdf 
Tal vez el primer autor que menciona la doctrina del pacto entre el monarca y su pueblo fue un monje alsaciano apenas conocido ni citado por los especialistas, Manegold von Lautenbach (1040-1119? $)^{69}$, quien a finales del siglo XI en plena controversia de las investiduras llegó a referirse en su obra Liber ad Gebehardum, compuesta hacia el 1085, a la existencia de un pacto entre en rey y su pueblo, y afirmó que la tiranía por parte del rey puede dar lugar a la deposición del monarca ${ }^{70}$. La teoría consensual del poder se atisba seis siglos antes de que John Locke construyera su teoría del pacto social.

A lo largo del siglo XIII civilistas y canonistas exploran el papel del pueblo respecto al origen divino del poder. Azo afirmaba que el titular del imperium era el pueblo que había cedido al emperador su ejercicio $^{71}$. A su vez Laurentinus Hispanus traslada la teoría de la universitas a los reinos exentos, y afirma que la titularidad del poder reside en el pueblo, que denomina universitas populi, de quien el rey lo recibe y lo ejercita ${ }^{72}$.

A finales del siglo XIII el conciliarista Juan de París publica De Potestate Regia et Papali, en la que se refiere a la Iglesia como unus populus, y afirma que el papa es la cabeza necesaria para mantener su unidad. Al retomar la cuestión planteada por los decretistas de si es posible deponer al papa, Juan de París afirma que sólo puede ser privado de su poder temporal por la autoridad humana, tanto por el concilio como por el colegio cardenalicio, pues actúan en nombre de la Iglesia $^{73}$. Una solución que posteriormente será aplicada vía conciliar para resolver el Cisma de Occidente iniciado en 1378.

\footnotetext{
${ }^{69}$ Inicialmente había sido un maestro laico itinerante para luego ingresar en la Orden benedictina, en 1094 resulta elegido prior del monasterio alsaciano de Marbach.

${ }^{70}$ C. WATner, cit., p. 75, siguiendo a M.T. SteAd, Manegold of Lautenbach, English Historical Review 1914, p. 113.

${ }^{71}$ B. Tierney, Religion, cit., p. 58.

72 J. A. Souto Paz, cit., p. 130-131.

${ }^{73}$ B. Tierney, Foundations of The Conciliar Theory, cit., p. 142-161.
} 
En 1315 el papalista Hervaeus Natalis ${ }^{74}$, publica dos breves tratados De iurisdictione $e^{75}$ y De potestate papae ${ }^{76}$, en los que se realiza la primera descripción de los poderes legislativo, ejecutivo y judicial, como integrantes de la potestad plena ${ }^{77}$. Y afirma con rotundidad que la jurisdicción se adquiere per solum consensum populi ${ }^{78}$, y lo aplica tanto al poder secular como al eclesial. Por lo que la doctrina del consentimiento popular adquiere una validez universal. Una formulación coincidente con las tesis de Marsilio de Padua y Guillermo de Ockham sobre la legitimidad del consentimiento. Y mientras Natalis defiende el centralismo y la monarquía papales, Marsilio prefiere el centralismo monárquico, y Ockham opina que la monarquía papal se estableció por razones de utilidad ${ }^{79}$.

En el siglo XV, en plena confrontación entre papalistas y conciliaristas durante la bicefalia pontificia que provoca el cisma de Occidente, las aportaciones de Francisco Zabarella y Nicolás de Cusa, son paradigmáticas en el desarrollo doctrinal del consentimiento en el seno de la Iglesia. Como también lo son las de los conciliaristas de la Escuela de París, también llamados sorbonistas: Jean Gerson, John Mair y Jacques Almain. Estos últimos por su aportación al desarrollo doctrinal de los derechos individuales pre-políticos, cuya formulación permite enlazar con el pensamiento constitucional de la modernidad.

Francisco Zabarella (1360-1417) ${ }^{80}$ en su Tractatus de Schismate escrito de 1403 a 1408, elabora una síntesis con las mejores glosas de

\footnotetext{
${ }^{74}$ Dominico de la Bretaña y profesor de la Universidad de París - dos años después de que Marsilio de Padua fuese Rector de esa Universidad en 1313 y diez años antes de que publicase Defensor Pacis- que será General de su Orden de 1318 a 1323.

${ }^{75}$ Edición de Paris 1506, localizable en la Bayerische Staatbibliothek (edición no digitalizada).

${ }^{76}$ Traktat des Herveus Natalis OP über die kirchengewalt von Ludwig Hödl. Max Hueber, München 1959.

${ }^{77}$ B. Tierney, Religion, Law, cit., p. 44 y s.

${ }^{78}$ De iurisdictione, Referido por B. Tierney, Ibid., p. 16 y s.

${ }^{79}$ B. Tierney, Religion, Law, cit., p. 52.

${ }^{80}$ Canonista formado en Bolonia, doctor en utrumque ius en 1385 y profesor en Padua hasta 1398. Jurista de reconocido prestigio tiene un papel muy notable en el concilio de Constanza.
} 
los decretistas y decretalistas para construir un sistema de gobierno coherente $^{81}$. Para ello se sirve de la doctrina de la corporación de la Iglesia universal que identifica como la congregatio fidelium en quien reside la autoridad corporativa. Según Zabarella el término Romana ecclesia no tiene un único significado y así puede referirse a la sede apostólica, al papa y los cardenales o a la Iglesia en su conjunto, congregatio fidelium. En ella el papa sólo puede ejercer los poderes conferidos por la propia Iglesia, que a su vez puede deponerlo si los trasgrede o incumple. Respecto a quien puede hacerlo en el seno de la Iglesia romana, Zabarella considera que los cardenales no podrían puesto que fueron quienes lo eligieron, de lo que derivaría una lógica restricción, pero sobre todo al ser una cuestión de fe la causa de su posible deposición sería competente el concilio general cuya autoridad es superior a la del papa: cum agitur de fide synodus maior est quam papa. Y de este modo demuestra en su síntesis que el concilio general puede deponer a un papa herético ${ }^{82}$. Al respecto no hace sino aceptar las tesis de los canonistas medievales Johannes Teutonicus en su Glossa Ordinaria y Alanus Anglicus.

Nicolás de Cusa (1401-1464) ${ }^{83}$ aporta una reflexión sustancial y conciliadora en su obra De Concordancia catolica escrita durante el Concilio de Basilea en 1432, en la que parte de la igualdad entre los hombres, por lo que sólo pueden someterse a la autoridad a través del consentimiento. Nadie como él hasta entonces había reformulado en una síntesis tan brillante los principios de gobierno, la legitimidad del poder, el consentimiento del pueblo, y el pluralismo unificado bajo la autoridad en una comunidad, que identifica como jerárquica e integrada por diversas corporaciones. Para Nicolás de Cusa la autoridad del papa es otorgada para la edificación de la Iglesia, no para

\footnotetext{
${ }^{81}$ B. Tierney, Foundations of The Conciliar Theory, cit., p. 199-214.

${ }^{82}$ J. Moynihan, Papal Immunity..., cit., p. 132 y s.

${ }^{83}$ Humanista de amplísima formación jurídica, que recibe en Padua, teológica y filosófica, que recibe en Colonia. Secretario de arzobispo de Tréveris en 1472 y profesor de Teología y de Derecho canónico en Constanza y Lovaina, participa en el Concilio de Constanza en 1431, y accede al cardenalato en 1448.
} 
su destrucción. Y en caso de enfrentamiento considera que el juicio del concilio debe prevalecer sobre el del papa ${ }^{84}$.

Jean Gerson (1363-1429) ${ }^{85}$ crea con su obra De potestate ecclesiastica una corriente doctrinal propia. En ella afirma que Dios otorgó la potestad eclesiástica a los hombres, quienes por razones de utilidad la delegan limitadamente al papa, en quien reside la plenitud de dicha potestad y en última instancia en la Iglesia y el concilio general, de ahí la importancia que le concede a la cuestión de la herejía papal y la superioridad de la congregatio fidelium sobre el papa ${ }^{86}$. Si bien la congregación de fieles debe ser presidida por el papa que garantiza la unidad cristiana y previene contra su dispersión ${ }^{87}$.

John Mair (1467-1550) ${ }^{88}$ en su influyente obra Disputationes de Potestate Papae et Concilii ${ }^{89}$, explora el vínculo jurídico entre el gobernante y su pueblo que compara con el existente entre el papa y los fieles en el contexto de la congregatio fidelium, que es depositaria de la potestad para legislar, juzgar y decidir. Y afirma con rotundidad que "el concilio, formalmente congregado, representando a la Iglesia universal, es superior al supremo pontífice" ${ }^{\text {. }}$.

Jacques Almain (1480-1515), discípulo de Mair y rector de la Universidad de París en 1597, escribe en 1512 el Tratado sobre la autoridad de la Iglesia y de los concilios generales contra los argumentos del ultramontano Tomasso de Vio, en plena polémica con

\footnotetext{
${ }^{84}$ Vid. el interesante análisis de B. Tierney, Religion, Law, cit., p. 66-71.

${ }^{85}$ Discípulo de Pierre d'Ailly, que era muy próximo al pensamiento de Ockham. Será Canciller de la Universidad de París desde 1395 hasta su muerte y participa en el Concilio de Constanza como representante de la propia universidad parisina.

86 “Tratado sobre la potestad eclesiástica y el origen de las leyes", en Conciliarismo $y$ constitucionalismo. Selección de textos, cit., p. 78-80.

${ }^{87}$ Ibid., p. 98 y s.

${ }^{88}$ Humanista escocés autor entre otras obras de los brillantes Comentarios a las Sentencias de Pedro Lombardo. Sus obras tendrán una notable influencia entre algunos de los reformistas puritanos como Calvino y John Knox, si bien él se mantendrá en el seno del catolicismo al igual que Erasmo frente a la reforma protestante.

${ }^{89}$ Cuyo texto se recoge asimismo en Conciliarismo y constitucionalismo, cit., $\mathrm{p}$. 171-194.

${ }^{90}$ Cfr., Ibid., p. 172.
} 
los tomistas de la Universidad de Toulouse. En él Almain compara los dos poderes espiritual y temporal y sostiene la semejanza estructural de ambos, llegando a equiparar la comunidad de fieles con la comunidad política, en tanto en cuanto el rey en su reino ejerce la jurisdicción en nombre de su comunidad política que le delega su poder, al igual que el papa lo hace en nombre de la Iglesia, como comunidad de fieles, y del mismo modo que la comunidad política puede deponer a su gobernante si se aparta de los fines para los que se le otorgó el ejercicio de la jurisdicción, la congregación de fieles puede destituir al pontífice que se extralimita en el ejercicio de su oficio ${ }^{91}$.

Los argumentos de los canonistas medievales sobre el consentimiento del pueblo como universitas, la soberanía dividida y los límites al ejercicio del poder no caerán en el olvido. Serán retomados a partir del siglo XVII ante el ejercicio despótico de los monarcas europeos. El primer ejemplo más notable es el inglés tras el triunfo de Cromwell y los parlamentaristas en la guerra civil inglesa de 1642-51 contra el absolutismo real de Carlos I, que será no sólo depuesto sino condenado y decapitado por traición en 1649. Treinta años después, John Locke, defensor de la revolución de 1688 en la que el Parlamento depone al último de los Estuardo, Jaime II, escribe su obra magna Two Treatises of Government. Una revolución que fortalece el poder del Parlamento inglés frente al poder real y facilita el nacimiento de la democracia parlamentaria en Europa.

\section{A modo de conclusión}

Resulta paradójico que los sistemas constitucionales contemporáneos permeados por una ideología laicista que parte de la separación rígida entre el modelo secular y el eclesial lleguen ingenuamente a vincular el modelo democrático contemporáneo al modelo ateniense o incluso al modelo republicano romano, aunque en realidad deban buena parte de su inicial formulación jurídica a los canonistas

${ }^{91}$ Cfr., p. 24 y texto completo de la obra de Almain p. 105-167. Para un análisis más detenido del tema vid. F. OAKLEY, Conciliarism in the Sixteenth Century: Jacques Almain Again, Archiv für Reformationsgeschichte LXVIII (1977), p. 111-132. 
medievales. Quienes desarrollaron entre otras: la bases de la noción de soberanía (jurisdictio), las teorías de la corporación (universitas) y la representación, la teoría consensual del poder (consensus), y los límites del mismo.

Después de todo la Iglesia Católica elaboró una estructura jurídica y un derecho propio que fue común a toda Europa occidental desde el siglo XII al siglo XV, y en palabras del historiador británico Lord Acton de finales del siglo XIX ${ }^{92}$ : el multisecular conflicto entre Imperio y Papado facilitó el nacimiento de las libertades públicas.

\section{Medieval Canonists and their contribution to the contemporary constitutional theory}

The contribution of medieval canon lawyers regarding to the development of the legal bases of contemporary constitutional thinking is analyzed in three areas:

1. Origin and development of the principle of sovereignty, from the concepts of jurisdictio and potestas. Papal sovereignty and its limits, from the doctrine of plenitudo potestatis.

2. Relationship between individual and collegiate power from the legal abstractions of universitas and persona representata.

3. Their contribution to the consensus theory of power and doctrinal development of the concept congregatio fidelium.

Palabras ClaVe: derecho medieval canónico, soberanía papal, colegialidad, teoría consensual del poder

Key Words: Medieval Canon Law, papal sovereignty, collegiate power, consensus theory

Nota o Autorze:

Prof. Gloria M. Morán García - Catedrático de Derecho Eclesiástico del Estado (Chair: Law, Religion \& Public Policy) Departamento de Derecho Público Especial. Facultad de Derecho (School of Law) UDC. Universidad de A Coruña, España.

\footnotetext{
${ }^{92}$ Cfr. B. Tierney, Church Law and Constitutional Thought in Middle Ages, cit., p. 8.
} 